\title{
APPLICATION AND OPERATIONAL RESULTS OF TECHNOLOGICAL PACKAGES TO ELIMINATE THE HUMAN OPERATION AROUND THE EAF AND IMPROVE THE SAFETY LEVEL*
}

\author{
Ivo Filipovic ${ }^{1}$ \\ Walter Cargnelutti ${ }^{2}$ \\ Giovanni Londero ${ }^{3}$
}

\begin{abstract}
The steel melting process in an Electric Arc Furnace is a complex set of tasks, coping with highly dangerous hazards as fire, explosions, uncontrolled reactions, hot metal projections and gas or dust emissions. Melt shops are dangerous working areas for operators, recording statistics with a high frequency of injuries. In the past years, without dedicated safety equipment, there wasn't a real attitude to the risk prevention. The paper describes the available technological packages to eliminate the manned activities on the melting floor, with the aim to prevent accidents and keep furnace operators safe. The technological packages suite extends the automatic control of the EAF melting process to all the operations from charging phase to tapping. Plus, the integration of the most frequent operations by automated specialized tools effectively minimizes power-off times, enhancing reliability and improving the transformation costs.
\end{abstract}

Keywords: Automatic electric arc furnace; Safety human operation; Risk reduction. 


\section{INTRODUCTION}

The continuous effort to optimize the operating costs and to enhance the plant performances in terms of productivity have brought the modern steel shops to produce more in shorter tap to tap times.

The evolution process of the electric arc furnaces has progressively transformed those melting units in complex metallurgical reactors, where several concurrent operations are taking place at the same time. Specific technologies have been developed and introduced through the years under the comprehensive supervision of sophisticated and reliable control systems. They made it possible the application of ultra-high electric power (over $1000 \mathrm{kVA} / \mathrm{t}$ ), progressively increasing the chemical energy input share and the melting rate. This persistent trend of development (fig. 1) led to reach power on times as short as 30 to 33 minutes to melt $120-130 \mathrm{t}$ of scrap to liquid steel.

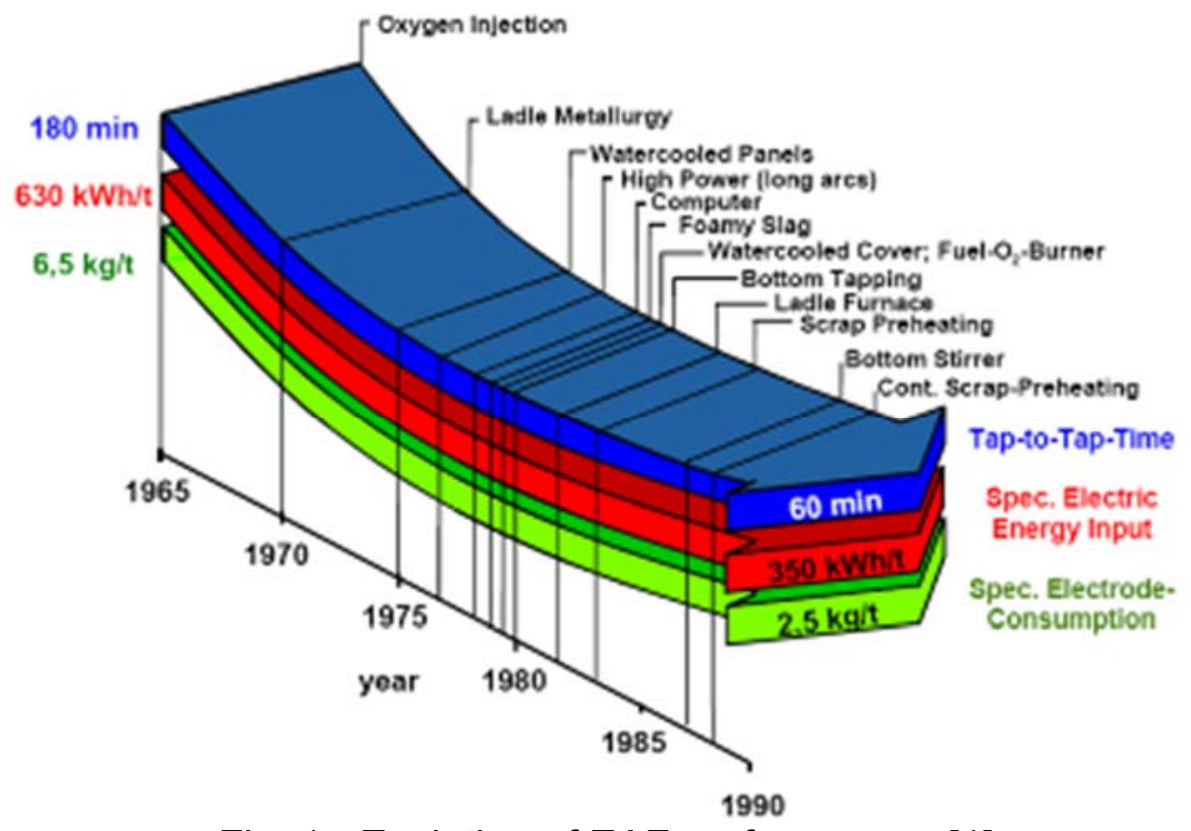

Fig. 1 - Evolution of EAF performances [1]

However, the operations involved in the melting process are requiring some tasks that, in most cases, are still performed manually.

Steel sampling, sill clearing, tap hole cleaning and sanding are recurrent operations that require skilled personnel and coordination to be fulfilled. Regular inspections of the refractory lining and water-cooled panels are required; occasionally gunning or panel substitution are demanded.

Regardless all the best personal protective equipment, training and careful operating practices adopted [2], the risk exposure is very serious, and statistics report that severe injuries and fatalities are still happening.

In the United States, for instance, the records of fatal injuries in the Iron and steel industry reported by the bureau of labor is showing that several cases per year are occurring (fig. 2). Among them, a few are connected with operations in the melting cycle, mainly exposing operators to heating injuries, oxygen back flashes or blasts. 


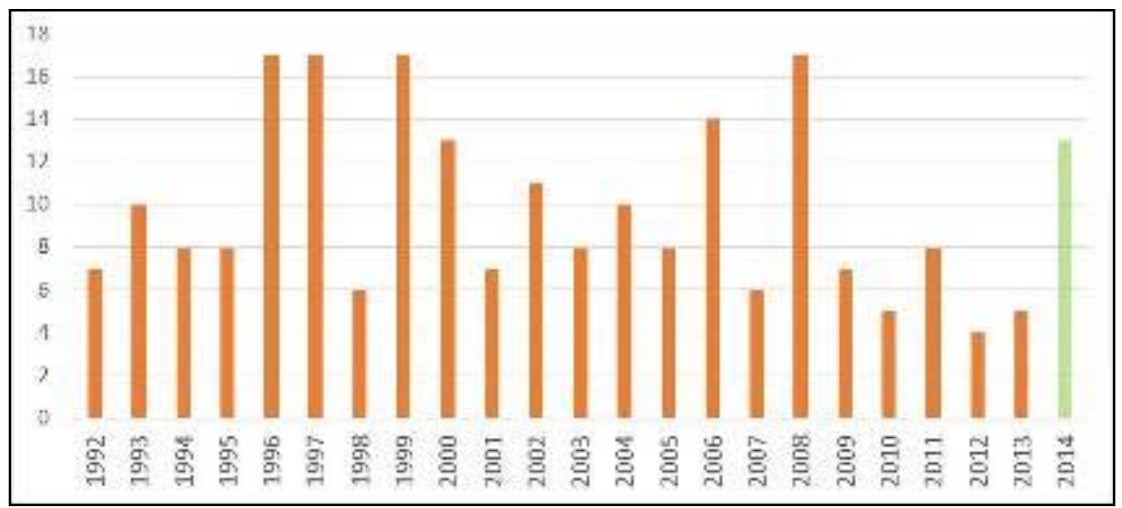

Fig. 2 - Number of fatal injuries in Iron and steel Foundries in US by year [3]

Along the years the continuous efforts to improve productivity and operative expenditure, put increasing pressure in reducing the power-off time, tightening the turnaround period down to few minutes [4]. However, it is universally recognized that just speeding up operations without reengineering the operational procedures is exposing the personnel to increasing risks of operational mistakes causing injuries. At the same time, safety operating procedures and space confinement are often posing limitations and interferences with the process, slowing it down. In real life, safety prescriptions are very often unwelcome by the personnel, considered as useless complications more than contributions towards better working conditions.

Even management in the past frequently considered safety as a non-productive matter, generating expenditures without direct benefits on throughput [5]. This vision is outdated today: safety in operations and selection of technological equipment is a top priority.

Injuries and workplace accidents are generating both direct and indirect costs: production loss, machinery damage, loss of working hours, compensation to injured workers, possible fines, plant impoundment, ...

In addition, specific government laws, standards (EN ISO 12100, EN ISO 13849) and federal directives (e.g. Machinery Directive 2006-42-EC) are posing explicit obligations to the steelmakers, equipment suppliers and machinery end users. The win-win approach to combine safety and productivity is offered by technology.

MORE has been dedicating to the design of specialized equipment to replace the manned operations in melt shops for more than 20 years, working side by side with the top steelmakers, supporting their needs for reliable automatic tools to remotely control and fulfil the EAF operations in the shortest times.

This process of continuous improvement has generated a complete suite of proven mature solutions enabling the personnel to fulfil all the required operations safely and reliably from the control room.

All the technological packages are fully integrated with the most modern automation control systems, in order to operate automatically, coordinated with the main working cycle. Thanks to the smart interface, they are doing most of the job independently requiring only the supervision of the personnel in a safe location. 
Eliminating all the manned exhausting recurring operations that were required in the past, immediate benefits in terms of productivity throughput are obtained. At the same time, part of the personnel, free from the previous demanding duties, can be dedicated to different activities.

\section{Recurring Operations}

Some operations are required at each EAF cycle:

- Clearing the sill of the slag door;

- Taking a steel sample and probing the melt temperature;

- Inspecting the tap hole after tapping and sanding.

These activities are consuming time and expose operators to severe risk of injuries. Operations at the door are prone to sudden reactions that are occurring rarely, but are highly unpredictable.
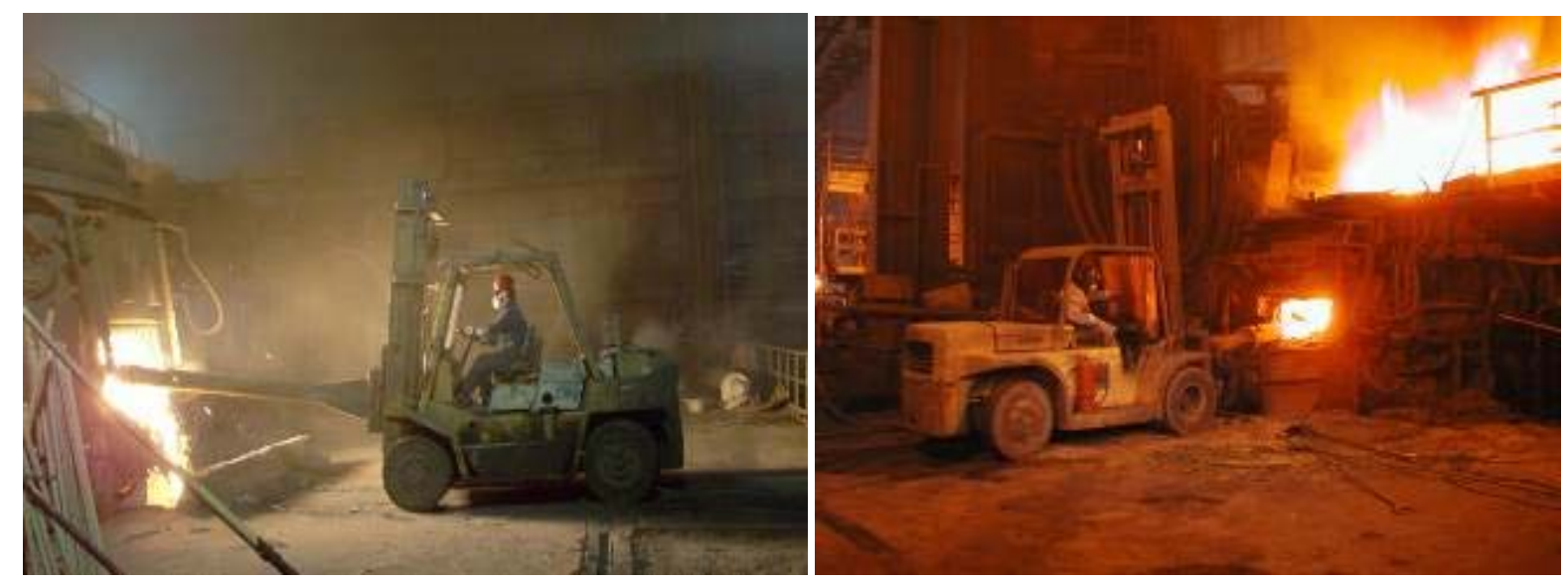

Fig. 3 Slag door clearing operations

In some steel shops the practice to switch the electrical power off prior to approach to the furnace floor is compulsory by the Company safety rules. In few countries, law already prescribes it. Switching the electrical power off is of course consuming time and interrupts melting but, above all, is suppressing the foaming slag process that is taking time to rebuild again.

In most steel shops the practice to allow the personnel to operate at the slag door with the power on is still a diffused habit. At the occurrence of a boil reaction or a sudden blast, any workers close to the furnace are exposed to severe injuries, regardless the safety equipment they are wearing. 


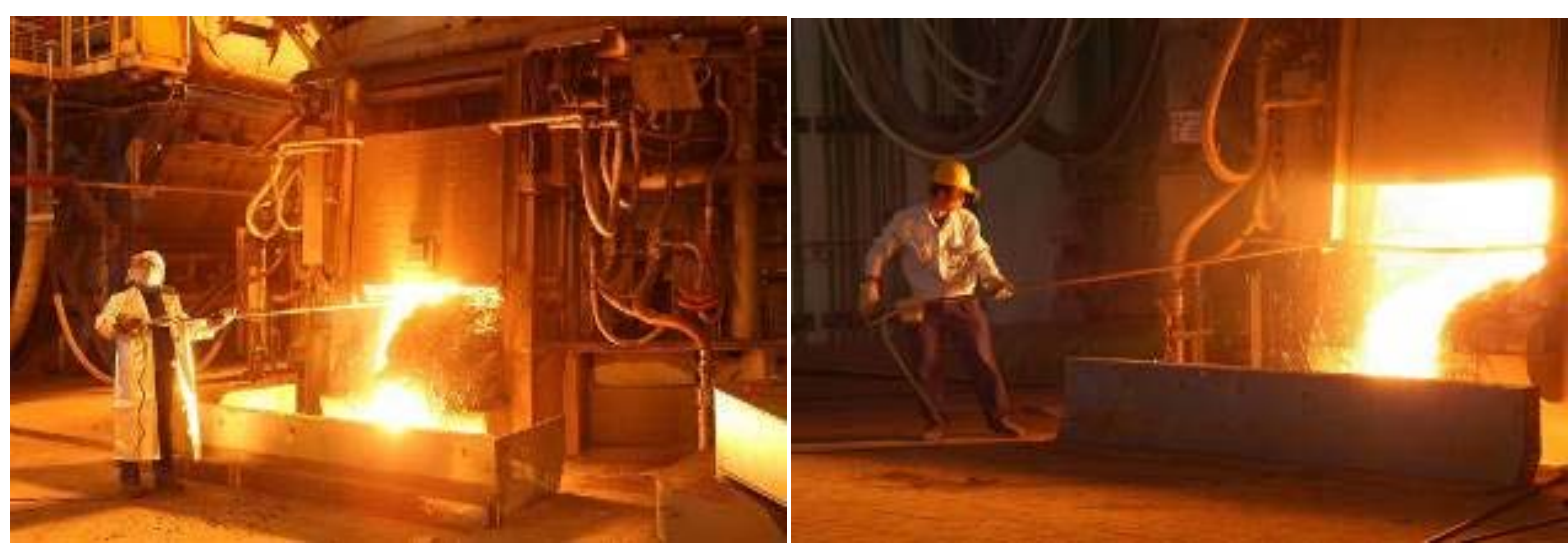

Fig. 4 Operators taking a sample or a probe

The tapping operations may be regarded as the most critical of the overall furnace cycle. In less than 3 minutes, more than $100 \mathrm{t}$ of liquid steel at a temperature higher than $1630^{\circ} \mathrm{C}$ are transferred into the ladle by a stream as fast as $5 \mathrm{~m} / \mathrm{s}$. Normally, when the flap at the EBT swings away, the stream is free-opening and the tapping operations can immediately start. Sometimes the stream is not opening spontaneously. In this cases, the tap hole requires oxygen lancing to be cleared from any clogging. In such an unlikely event, a skilled operator is required to approach to the EBT area from the bottom with a bent pipe to lance the tap-hole and clear it by oxygen from few meters distance.

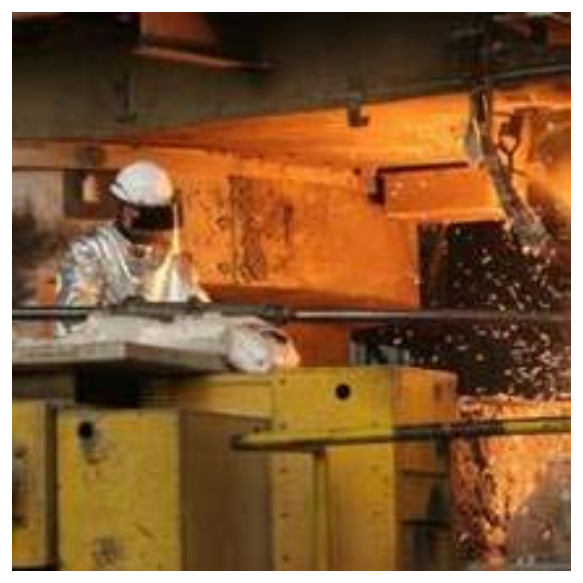

Fig. 5 - Operator lancing the taphole

At the sump area, after tapping operations, the tap hole needs to be inspected, eventually cleared from slag residuals and filled in with sand. This operation is requiring to the helper to walk to the EBT balcony to perform the required actions. 

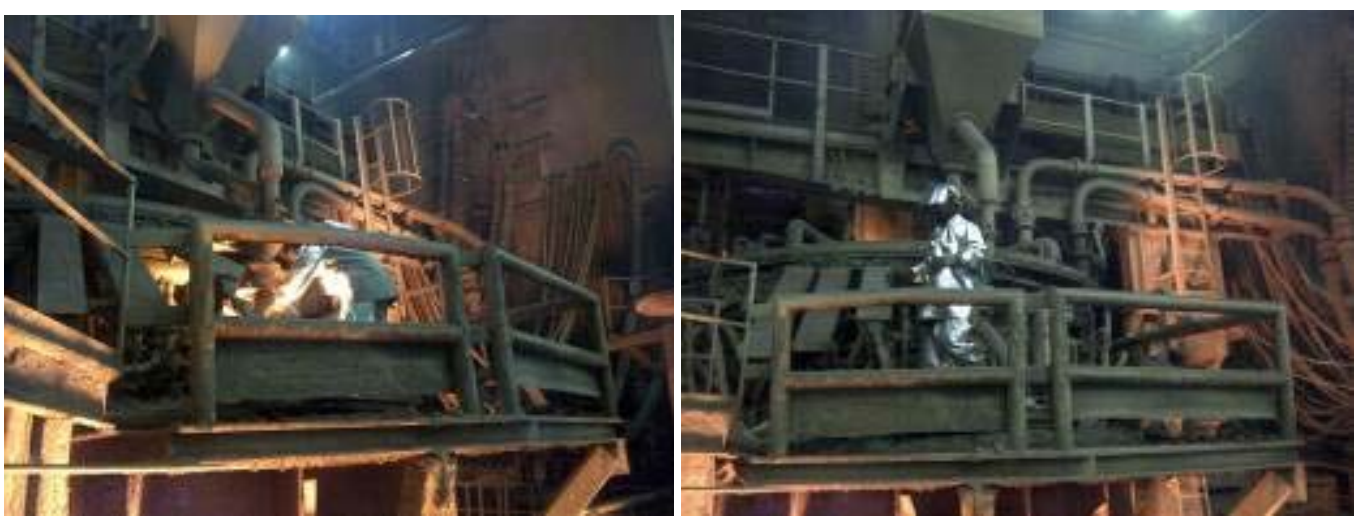

Fig. 6 - Operator at EBT balcony

In case of incomplete melting, residuals and skulls may fall in the area, obstructing the tap-hole sleeves. The efforts to remove the obstructions can be sometimes very difficult to fix and time consuming.

All these operations entail unpredictable time losses, exhausting man labor in hazardous conditions (restricted space, heat, dust, hot sparks projections, operating with oxygen,...) and posing high risk of injuries, resulting in higher production costs.

\section{Guiding Design Principles for Automatic Technological Packages}

A skilled engineer, approaching for the first time to the EAF process, may guess why the required technologies to perform these functions have not been native since the origins of the modern electric arc furnace. At a deeper insight, he will realize that simply adding equipment to fulfil individual actions will not work in the steel shop environment.

Neighborhoods of an electric arc furnace are a tough environment for any mechatronic application to survive. Dust, heat loads, flames, electromagnetic effects, falling loads, ... pose any equipment in great difficulty. Moreover, the space for the equipment to fit is most of the time very restricted, limiting the degrees of freedom for the possible design solutions.

The tasks described above, which would be easy for a skilled person to fulfil, are not easy to perform by machines.

Therefore, the equipment functionality, i.e. the capacity to fulfil the required task in a practical, user-friendly manner, is guiding our design concept.

Beyond the technological package functionality, in our experience reliability of the equipment is a mandatory keystone, a top priority. Very often we saw complex pieces of equipment installed close to EAF failing and, besides not performing the functions they were designed for, creating themselves disruptions and supplementary workload or, even worse, obstacles and higher safety risks for the workers.

Finally, we're well aware that any piece of equipment may fail, by accident. Careful attention for easy maintainability by the technicians and the tools available in a steel shop is integrated in the machine design and the control functions of all packages. 
Maintaining the slag door's sill clear from scrap or skulls build up is very important for efficient steelmaking process. By performing all the operations during the arc melting is not only beneficial for the production throughput, but it is also improving the effectiveness of the cleaning action and the metallurgical process.

MOTANK is a remote controlled ram, specifically designed to operate at the slag door. The cart is independently moving on rails, that can be laying in axis with the door or eventually sideways to best fit in almost all the layouts, even in case of EAFs encapsulated in a doghouse. The ram is actuated by a hydraulic cylinder equipped on-board. The pulling force is designed to easily clear the scrap and skulls in all the situations. It can be also tilted downwards to better fulfil the clearing action. The reaction forces are directly transferred through the cart frame to the floor by locking pins.
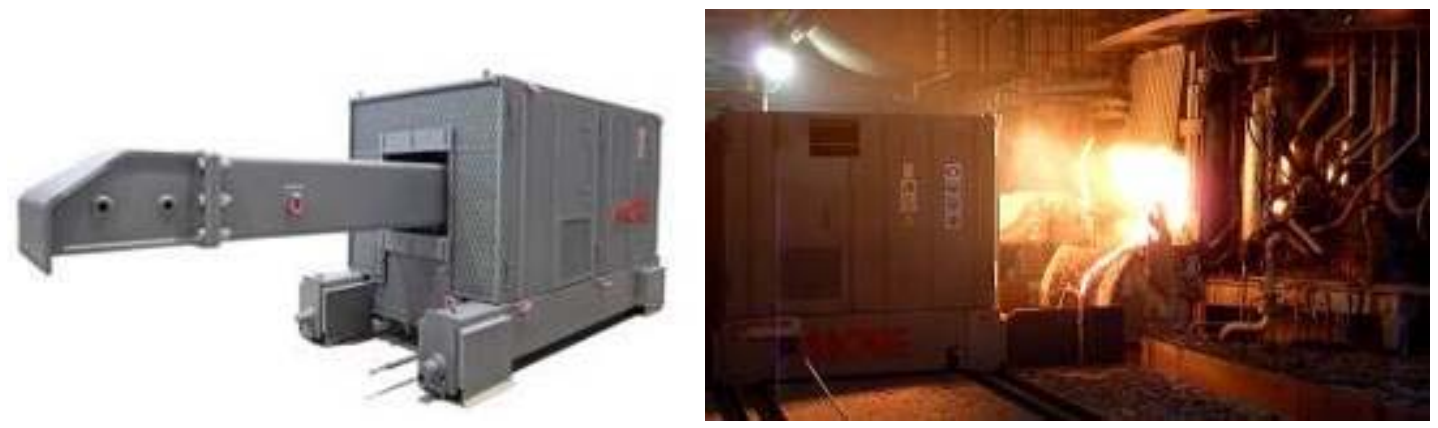

Fig. 4 - MOTANK

The MOTANK operating cycle starts automatically under the supervision of the melter from the control room. The clearing operations are performed during power-on time in a reliable and predictable way without interfering with the melting practices. Upon exception still the operator may remotely control the ram functions by direct commands.

Once the clearing operation is completed, the MOTANK automatically recovers in a parking position, farther from the furnace. Any maintenance or check will take place in the parking position. The study design and the flexibility of use acknowledged high appreciation by the steelmakers and proven by the long reference list of installations.

In quality steel mills, the MOTANK proved itself as a very effective tool for dephosphorization purposes. Early deslagging is playing a key role in the metallurgical process. Sill clearing, coordinated with the appropriate timing and with the slag forming practice, is automatically started by the melting profile and is promptly performed on time, thanks to the extremely reliable pulling force. As an example, consistent dephosphorization results with concentrations lower than 80 ppm have been achieved in the production of rail wheel grades after installing this technological package.

The proven reliability of the MOTANK in clearing the slag door is giving in turn further benefits and operative advantages in other functions:

- Sampling and probing are more effective, safe and reliable;

- Sill clearing is not required during turnaround; 
- Residual frozen soft foamy slag is self-protecting the sill (no need to use dolomite on the sill)

Automatic Sampling: Catfish

The first EAF sampling manipulator designed and installed by MORE dates back to 1997.

Along the years, the equipment evolved to a mature version that has been optimized up to the minimum details. Nowadays, the CATFIS manipulator is reaching the top standards of availability, requiring close-to-zero maintenance and a functional easyto-use interface for steel shop technicians.
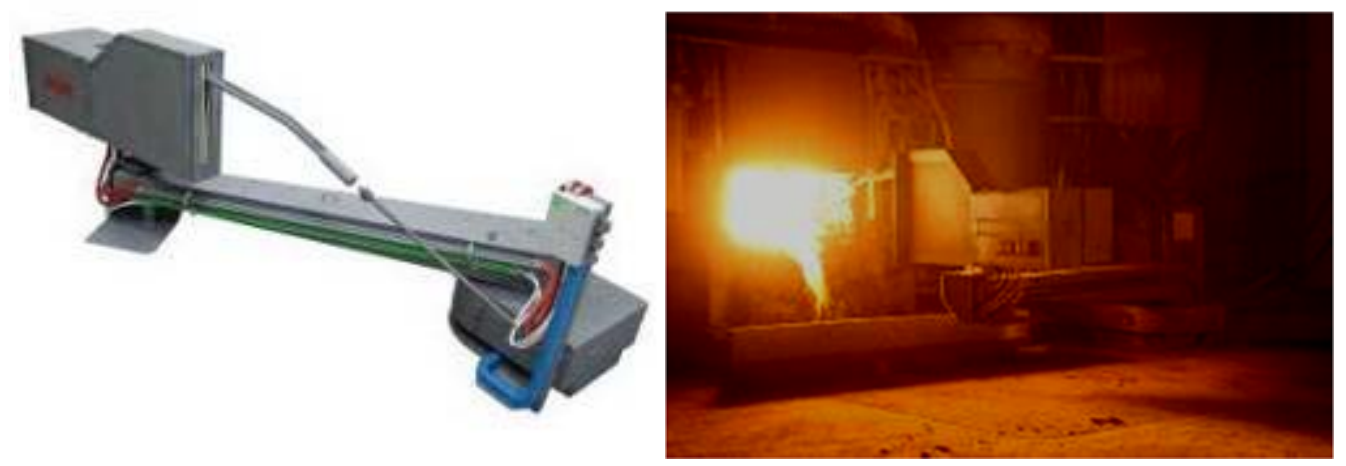

Fig. 5 - Catfis

The classical version of the manipulator has a swinging movement around two axis of rotation in order to approach from the parking point to the measuring position. The terminal arm is water cooled, in order to guarantee a long life and a proper protection for the cabling and the measuring lance sensor. All the mechanical components are carefully shielded from heat and slag radiation by metallic protections. Once in the measuring position, a linear actuator is inserting the lance in the bath along a calibrated curved trajectory. In order to perform a reliable measurement, the lance insertion movement is controlled in speed and position. In case of collision detection, the manipulator automatically retracts the lance in order to avoid further damage.

The insertion depth can be varied according to the steel bath level and the refractory wear. This functionality is very useful, particularly in the application to continuously fed furnaces operating at flat bath conditions facing a wide range spanning of the bath level.

The CATFIS manipulator is designed to move to a parking position far from the furnace, where the operator can change the cardboard in a safe and protected workplace. In EAFs installed in a doghouse, the parking position is designed to fit the lance into an opening to allow for the cardboard change from outside.

Complete compatibility with all the OEM measuring systems and cardboards has been provided along the years. Further process integration has been developed by MORE technologists in close cooperation with DANIELI R\&D, in creating a reliable mathematical model to track the bath temperature in real time starting from the measurements taken [8]. A virtual soft sensor is generated to provide to the operator 
useful information as the bath temperature evolution and the missing time to tap. The benefits of a closer and more reliable endpoint prediction are detailed in a dedicated paper [9].

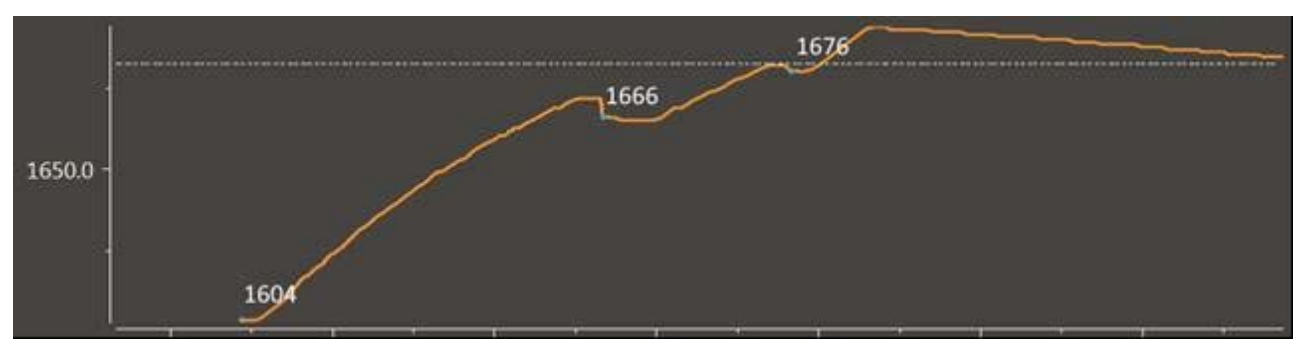

Fig. 6 - Real time bath temperature tracking

Today our main concentration to further enhance operators' safety in performing the sampling operation is the provision for an automatic cardboard changer. Many suppliers have been proposing different solutions. However, the availability and reliability of the equipment is still low, requiring frequent intervention by maintenance personnel. The cardboard replacing operation, which a man can easily perform in few seconds, for a mechanical equipment is a fairly more complex task than it can be theoretically expected, mainly due to the deviation of the lance from the nominal position and misalignment. The engineering team has been thoroughly analyzing the failure modes of existing systems and defining the functions of the automatic cardboard changer to eliminate the failing factors or to walk around them. The analysis highlighted that cleanness, flexibility and larger fitting tolerances are the clues for a reliable machined operation. A brand new design concept has been developed. The first prototype (fig. 9) is currently under testing and consolidation in our factory and will be readily available as an improvement kit to be applied on existing CATFIS manipulators.

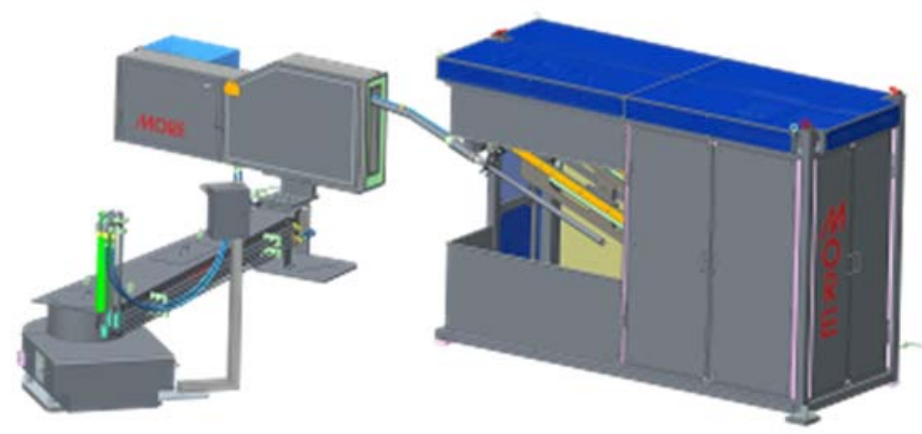

Fig. 7 - Automatic Cardboard Changer

The process of substitution of mechanical actuators with electrical motors with drive control is a persistent trend to simplify the equipment, increasing the dynamics flexibility and control management. It is opening several interesting opportunities to integrate in the manipulator new smarter and very useful functions. A multiple axis manipulator (Fig.10) has been already designed and constructed. It is installed in a German EAF producing stainless and high grade steels during late summer. 


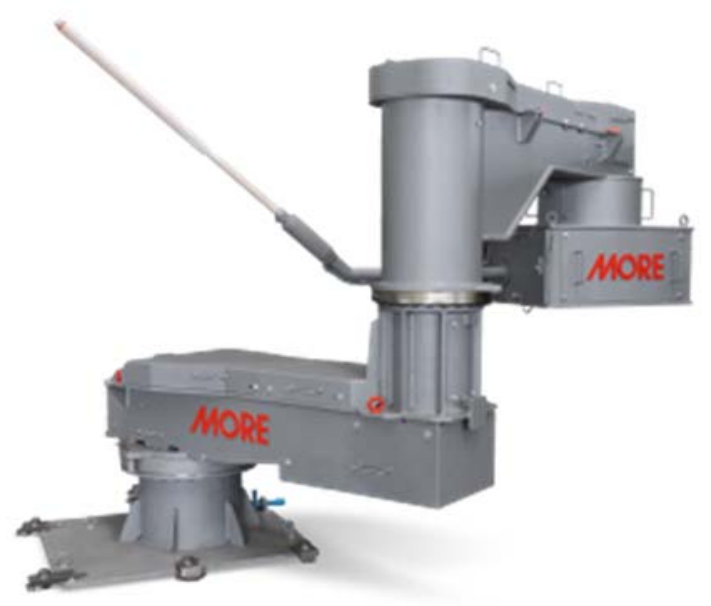

Fig. 8 CATFIS 2.1

Multiple axis manipulator advantages: flexibility and compactness to be fitting in constrained and confined areas, total control of movement and adapting trajectories, easy maintenance, automatic cardboard change, tailored for the steelmaking harsh environment and multi-tasking operations.

Taphole Inspection and Sanding: EBT eye/ebt sand/auto-sand

Besides the slag door area, also EAF sump area and operations involved during and after tapping are another challenge for operators. After tapping, the tap hole inspection is commonly made just by a visual inspection.

The idea to perform the inspection from a remote position to the control room is dating back to the beginning of 2002 by adopting a camera. The biggest issues to solve were concerning the installation of the sophisticated electronic equipment, keep optics clean have correct exposure and frame rate in order to obtain clear and highresolution imaging in highly variable illuminated conditions.

A long process of optimization involving many engineering competences brought about the solution of EBT EYE, an integrated package adopting the highest standard state of the art digital cameras tailored with a proprietary vision firmware to enhance the dynamic response and resolution of the imaging in all the EAF operating conditions (fig.11).
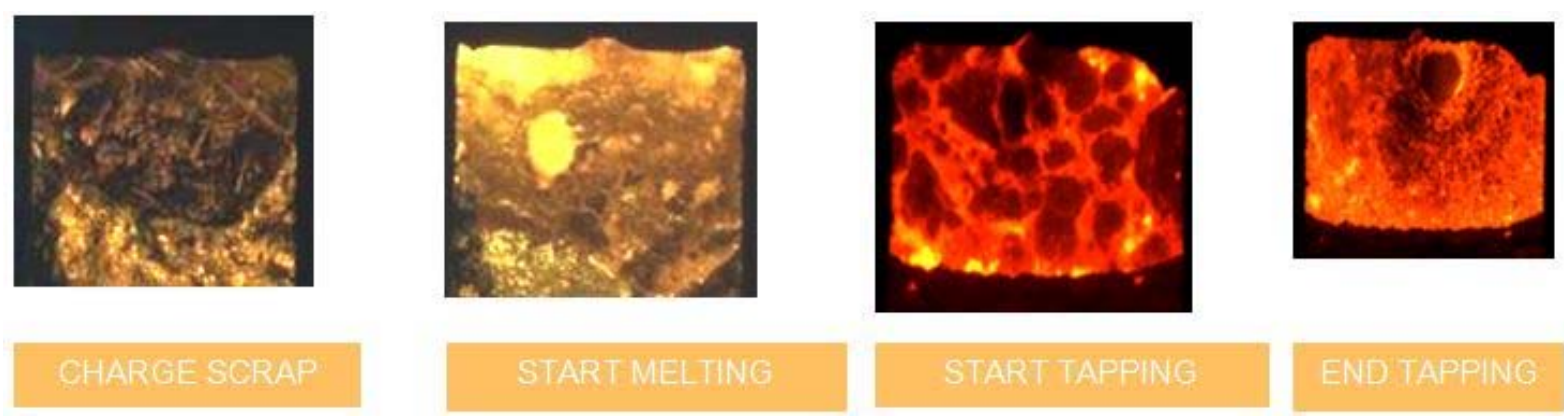

Fig. 9 - EBT EYE imaging 
Besides the quality of imaging and remote vision, the EBT EYE installation has demonstrated a high standard of availability, that is one of the most important performance priorities of the equipment, requiring basically only periodical routine checks. The EBT EYE is cooperating with the automatic sanding equipment EBT SAND.

Different solutions have been developed and installed to obtain the best result in terms of layout fitting and reliability. The on board solution (fig. 12) is a compact allin-one design assembled on a sliding guide. A local small bin is delivered with the proper amount of sand by a small stationary dispenser, located close to the furnace to be charged by big-bags. The EBT EYE is mounted parallel to the feeding chute in order to check in real time the correct feeding of the material and tap hole status.

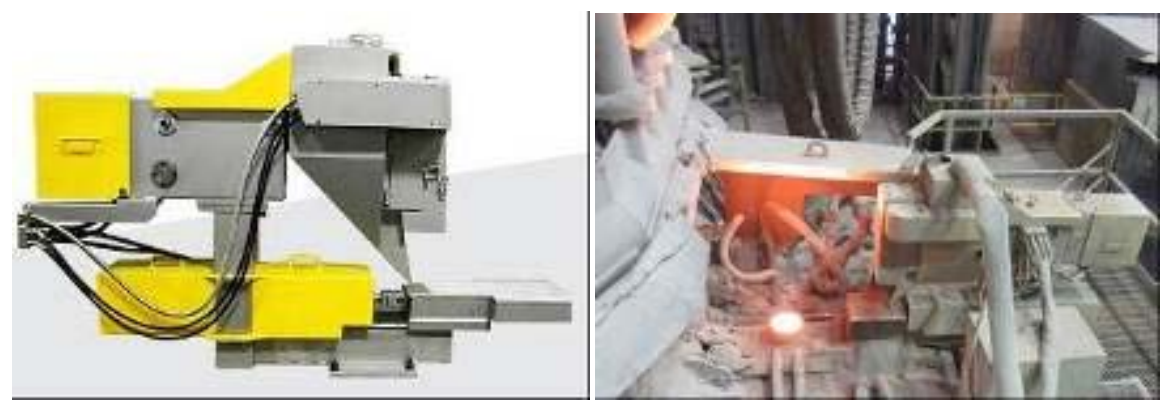

Fig. 10 - EBT-SAND (on board version)

The whole sequence for the tap-hole turnaround is averaging less than 30 seconds. The operator can start it immediately after the furnace tilt-back and level the furnace immediately after. In case of any clogging eventually requiring lance cleaning, the entire package will be moved in the park position, eliminating any interference for the access to the sump area.

After the fulfilment of the operation, the EBT window will be covered to avoid flaming, slag overflow or hot metal projections during scrap loading and melting. The on-board version is particularly dedicated to flat bath operation, when the roof is rarely opened swinging over the sump area.

Another version has been specifically developed for off-board installation and it's called AUTOSAND. Having all the equipment installed far from the furnace enhances the reliability of the system and reduces the maintenance efforts. In case of frequent shell change practice, only one system is required. 

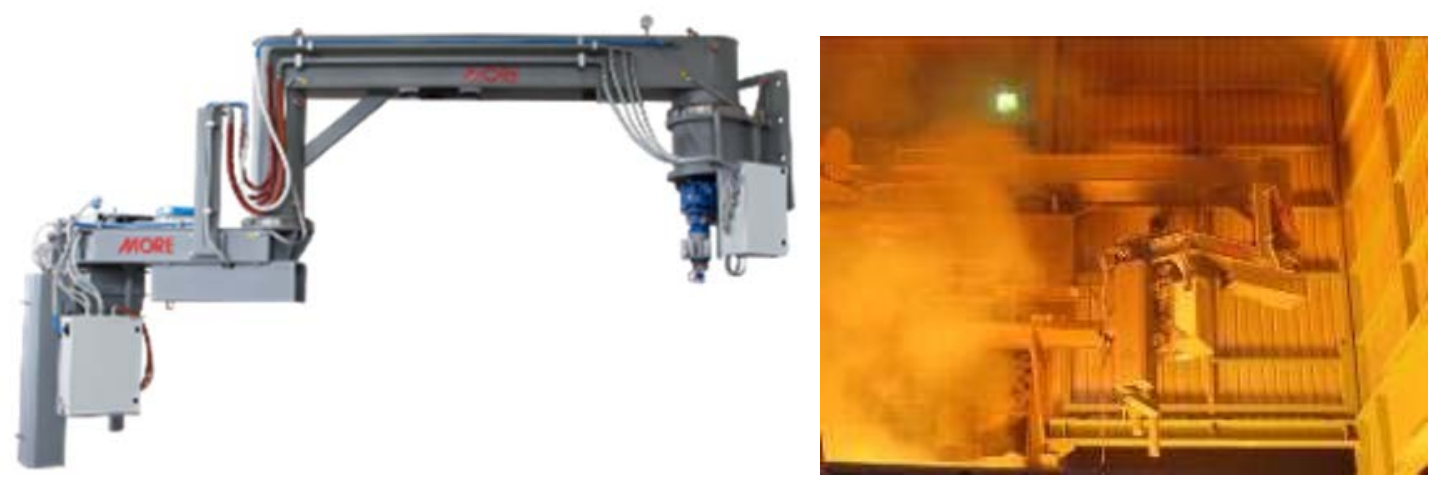

Fig. 11 - AUTOSAND (off board version)

\section{Taphole Lancing: Stap}

The STAP manipulator is a multi-axis equipment dedicated to lance the tap hole in case of clogging in order to open the steel stream.

All the actuators are electrically driven and controlled with high accuracy via absolute encoders.

The equipment is normally parked offline, armed with a special pipe, ready for use. In case of non-spontaneous opening the operator starts the cycle from the control room and the STAP automatically inserts the lance in the tap-hole. In order to center the sleeves the reaching is adjusted according to the platform tilt angle. Once the lance is in the correct position, oxygen lancing starts together with the vertical movement.
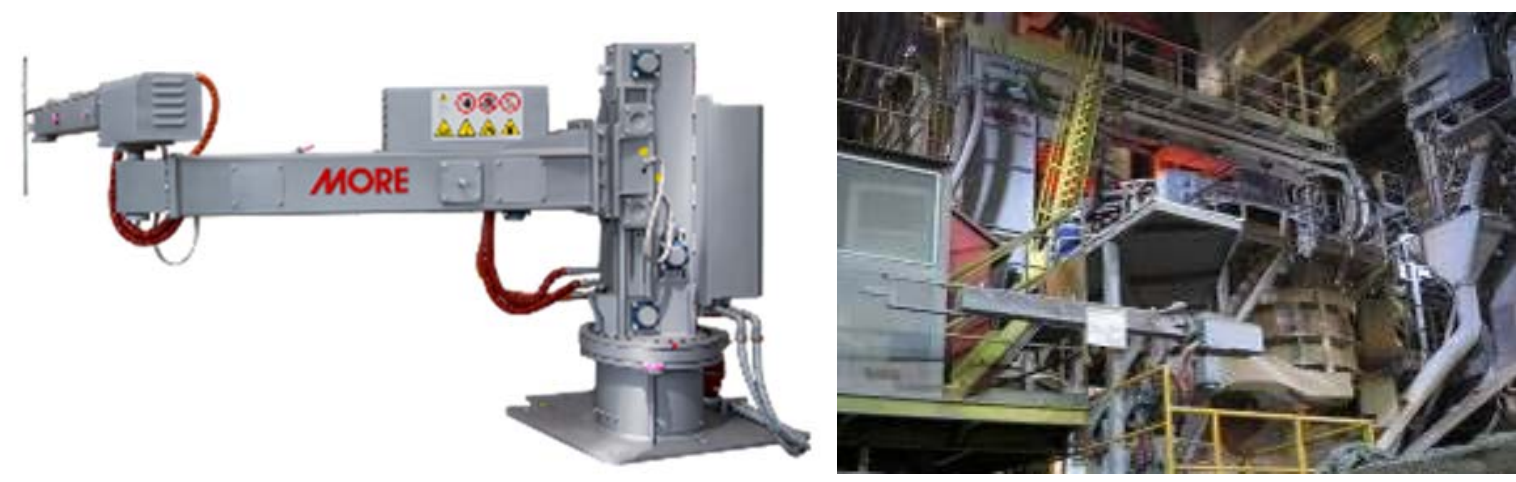

Fig. 12 - STAP manipulator

The STAP device is not used regularly at each cycle, but only when required. Nevertheless, it saves a lot of long delays that usually are accumulating in several steel shops due to the time required for operators to get prepared at the occurrence of the non-spontaneous opening. On the other end, the already mentioned safety related advantages are the main quality of this application. 
Taphole Clearing: Strop

Unmolten scrap, skulls or heavy residuals may obstruct the tap hole after tapping, precluding the possibility to correctly fill the sand. Sometimes obstructions are drilled by the operators by oxy-cutting. Moreover, lancing is non effective in case of slag skulls, concrete or graphite blocks. These tasks, although not very frequent, normally generate long delays, sometimes hours. Production loss and cost associated, plus hazard to damage the sump panels with injuries risk for the operator represent a very serious issue.
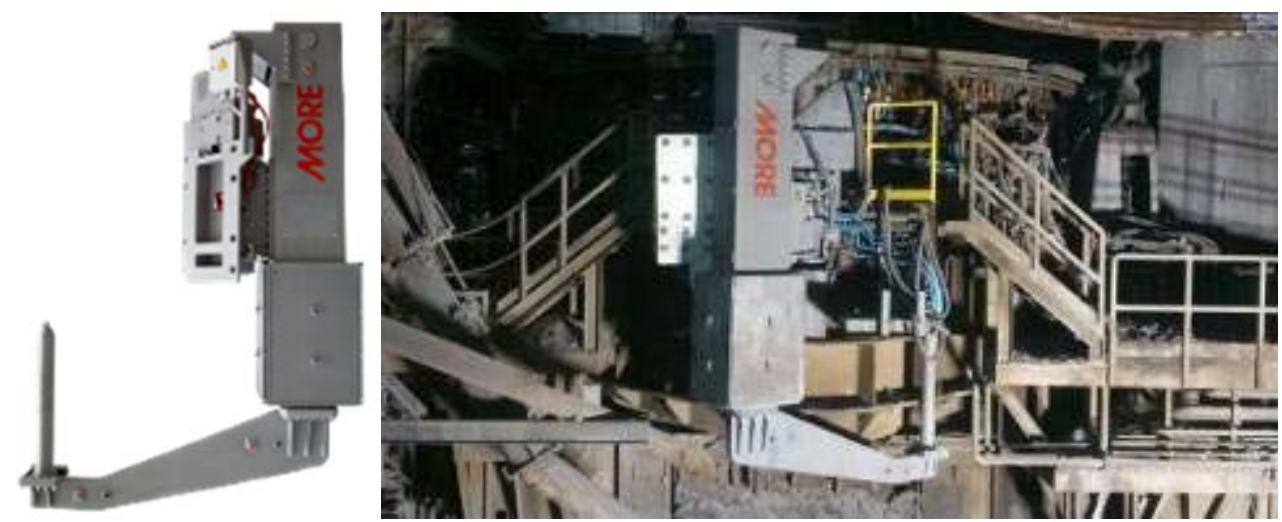

Fig. 13 - STROP in operation on the EAF in Mexico

The STROP is a hydraulically actuated equipment that inserts a sturdy rod into the tap hole that is able to lift heavy loads and free the tap hole from any kind of obstruction.

\section{CONCLUSION}

Productivity and safety nowadays can be integrated with the adoption of effective technological packages to fulfill all the recurrent operations in the EAF melting cycle automatically.

MORE attention for reliable and functional design of equipment proves the practical effectiveness of the solutions in several steel shops, shrinking the power off times to few minutes. Automatic slag door clearing, sampling and probing by remotely controlled manipulator and tap hole inspection and sanding are well established state of the art tools for MORE customers.

Newly developed technological packages prove very effectively to reduce the delays in case of accidental clogging of the EBT. The manipulators STAP for EBT lancing and STROP for tap hole mechanical unclogging and pocking prove very effective to reduce delays in the first pioneering installations.

The continuous efforts of MORE designers and technicians to improve the safety and productivity is currently focusing to integrate also other functions. 


\section{REFERENCES}

1 J. SZEKELY, G. TRAPAGA, Stahl und Eisen, Vol. 114, 1994, No. 9, p. 43-55

2 BUREAU OF LABOR STATISTICS, Occupational Injuries and IIInesses and Fatal Injuries Profiles, Industry (2014).

3 COMMITTEE ON HUMAN RESOURCES WORKING GROUP ON IMPROVING STEEL PLANT SAFETY, Accident - Free Steel, International Iron and Steel Institute, Belgium (1999).

4 M. PIAZZA, M. OMETTO, Process control and optimization through a modular approach to EAF automation: the "Automatic EAF" concept, Metec Proc.\&2nd ESTAD, Düsseldorf (2015), p. 439.

5 S. MIANI, A. FORNASARO, L. GEMO, M. MILOCCO, Safe and Productive Electric Arc Furnaces, Iron \& Steel Technology, Pittsurgh (Jan 2014), p. 68-78

6 CEC Occupational Accidents, Iron \& Steel Industry: Results of Annual Surveys 1977 1981. Occupational Accidents 1, CEC (Eurostat), Luxembourg, 1983.

7 INTERNATIONAL LABOR ORGANIZATION, Code of practice on safety and health in the iron and steel industry, Geneva, 2005

8 S. GUANIN, V. DIMITRIJEVIC, M. PICCIOTTO, G. TRASSINELLI, Artificial neural network approach for molten bath temperature tracking on EAF/VD, SteelSim 6th International Conference, Bardolino, 2015

9 A.SPADACCINI, R. TURCO, F. BIANCO, M. PIAZZA, V. DIMITRIJEVIC, Operational results of neural network based temperature control in primary and secondary metallurgy in ABS steelmaking plant, EEC Conference, Venice, 2016. 